\title{
THE INFLUENCE OF IONIZING RADIATION ON THE BODY FLUID COMPARTMENTS OF PATIENTS WITH MALIGNANT LYMPHOMA ${ }^{1,2}$
}

\author{
By JOSEPH GREENBERG 8, 4 AND DANIEL LASZLO
}

(From the Division of Neoplastic Diseases, Montefiore Hospital, New York, N. Y.)

(Submitted for publication August 3, 1954; accepted November 3, 1954)

The effects of ionizing radiation have been studied in isolated cells suspended in various nutrient media as well as in intact animals. Alterations of varying degree-up to death-have been observed depending on the dose administered and the radio-sensitivity of the tissue exposed. Several mechanisms have been invoked and many substances have been implicated, but to date there still remain large gaps in our understanding of the nature of radiation injury.

Many of the changes occurring in radiation injury involve the fluid components of the body. Thus, necropsy examination of the Japanese who died from exposure to the ionizing radiation of the atomic bomb revealed edema of many organs (1). The most radio-sensitive tissues of the individual such as the lymphoid and hematopoietic tissues are highly fluid (2). Many of the symptoms of radiation sickness such as nausea, vomiting, diarrhea, shock, etc., are associated with changes in hydration.

The available literature contains several studies on the water content of organs and on the water balance of animals following exposure to ionizing radiation (2-10). There are also a few reports on the effects of total body $x$-radiation on some of the body fluid compartments of animals $(3,5,10,11)$. In these latter studies several of the workers found increases in the plasma and extracellular fluid volumes of their animals following exposure to ionizing radiation. However, most of these studies were "acute animal studies" employing radiation doses which resulted in the death

1 Presented to American Physiological Society, Atlantic City, N. J., April 16, 1954.

2 Supported in part by grants from the Damon Runyon Memorial Fund, and the Edward S. Abelson Memorial Fund.

- Trainee, National Cancer Institute.

- Present address: Radioisotope Laboratory, United States Naval Hospital, St. Albans, Long Island, New York. of the animal. Furthermore, very few of the measurements were performed simultaneously, or repeated serially in the same animal. Additional difficulties in interpretation result from the techniques employed in many of these studies, such as the use of thiocyanate ion to measure the extracellular fluid volume, and the dye methods to ascertain the plasma volume. Moreover, to our knowledge, there are no reports in the literature on the effects of ionizing radiation on the body fluid compartments of human subjects.

It seemed of interest, therefore, to investigate the effects of ionizing radiation on the body fluid compartments of patients receiving radiotherapy for malignant tumors. The determinations were carried out simultaneously and repeated serially in each individual, using deuterium oxide $\left(\mathrm{D}_{2} \mathrm{O}\right)$ to measure the total body water, inulin and/or thiosulfate to measure the extracellular fluid volume, and $I^{131}$-tagged human serum albumin (I.H.S.A.) to measure the plasma volume.

\section{PROCEDURE}

Four patients with malignant lymphoma were studied on the metabolic research ward for 60 to 126 days. The study was divided into a control, radiation, and postradiation phase. The control phase lasted a minimum of four metabolic periods ${ }^{5}$; the treatment phase was three to four periods in duration and the patients were then observed for two to three additional metabolic periods following the completion of radiotherapy.

During the entire study the dietary offerings were kept constant. Two of the patients (C. M. and G. E.) were maintained on a "normal" diet. This contained a daily average of 1830 calories ( 64 grams protein, 62 grams fat, and 254 grams carbohydrate). The other two patients (I. T. and S. C.) received a diet adequate in calories, but low in proteins and deficient in B-vitamins and certain minerals in an attempt to gauge what role the nutritional status may have upon radiation sensitivity. This latter diet was essentially a Kempner rice diet (12) modified only by avoiding those fruits which

\footnotetext{
5 A metabolic period consists of six days.
} 
had a high B-vitamin content and giving no vitamin and iron supplement. The daily allotment contained 2550 calories (26 grams protein, 2 grams fat, and 608 grams carbohydrate).

Serial simultaneous determinations of various body constituents including the body fluid compartments were performed before, during and after exposure to ionizing radiation. Nitrogen, phosphorus, calcium, potassium, sodium, and water balances were measured throughout the entire study. Urinary uric acid and creatinine determinations were performed daily. Clinical and laboratory data including roentgenograms, obtained at frequent intervals, supplemented the study.

Since in each of the four patients the metabolic balances, the urinary uric acid and creatinine excretions as well as the various blood constituents remained essentially constant, at least in the last two periods of the control phase, it seems justified to assume that by that time all the patients had achieved a "steady metabolic state." The values for the body fluid compartments obtained during these last two control periods served as the baseline for the values obtained during the radiotherapy and post-radiation phases (cf. Tables I and II).

Radiotherapy was given in the form of total body $x$-radiation to three of the patients (C. M., G. E., and S. C.), each receiving four exposures during the course of the three metabolic periods immediately following the control phase. The radiation was delivered from a Picker X-ray machine held at $200 \mathrm{kv}, 25 \mathrm{ma}, 1.6 \mathrm{~mm}$. $\mathrm{Cu}$ hvl, with $1.0 \mathrm{Cu}$ and $4.0 \mathrm{Al}$ filtration, distance $150 \mathrm{~cm}$. The skin dose to the patient's supine body was approximately $5 r$ per minute for a total exposure of 10 to $25 r$ per dose. The initial dose was given in the first part of radiation period 1 , the second dose in the first part of radiation period 2, the third dose at the beginning and the final dose toward the end of radiation period 3 . The first and third doses were administered to the anterior surfaces, the second and fourth doses to the posterior surfaces of the supine body. One patient (C. M.) received $10 r$ on the first exposure, and $15 r$ with each of the other three exposures, for a total of $25 \mathrm{r}$ anteriorly and 30r posteriorly. The other two patients (G. E. and S. C.) received $25 \mathrm{r}$ with each exposure for a total of $50 \mathrm{r}$ anteriorly and $50 \mathrm{r}$ posteriorly. Immediately after each exposure the patients were returned to their room in the metabolic ward.

The fourth patient (I. T.) received local radiation during the course of four metabolic periods via the Cobalt ${ }^{\infty}$ teletherapy unit, at a source skin distance of $80 \mathrm{~cm}$. with 0 angulation of beam head, and with an air dose of $30.5 \mathrm{r}$ per min. Except on Sundays, when no treatment was given, the patient received an exposure of 6.3 minutes each morning at 7:30 a.m. to each of two 13 by $15 \mathrm{~cm}$. fields, viz., left upper chest anteriorly and left upper chest posteriorly. The only modification was that on experimental days the radiation treatment was given in the afternoon, after conclusion of the experiment. A total of 18 such radiation treatments were given. The daily tumor dose from each field was $117 \mathrm{r}$ and the total tumor dose delivered was 4212r. Immediately after the completion of each exposure the patient was returned to his room in the metabolic ward.

After the post-radiation phase was completed the patients were discharged from the metabolic ward. Those patients who were maintained on the "restricted" diet were then re-studied 35 to 39 days after being placed on a diet comparable to the "normal" diet given on the metabolic ward (cf. Table II).

\section{MATERIALS AND METHODS}

The volume distribution studies were performed in the resting post-absorptive state with no sedation and the subjects recumbent. A multi-eyed urethral catheter was passed into the bladder for urine collections. Blood samples were obtained without stasis through an indwelling needle (Cournand) placed in the femoral artery. The blood was permitted to clot when the samples were to be analyzed for thiosulfate and $\mathrm{D}_{2} \mathrm{O}$. Liquaemin (Hoffman-LaRoche), $0.1 \mathrm{ml}$. per $10 \mathrm{ml}$. of whole blood, was used as an anticoagulant in specimens drawn for inulin and I.H.S.A. determinations.

The heavy water space was measured as the two-hour volume of distribution of intravenously injected deuterium oxide. The $\mathrm{D}_{2} \mathrm{O}$ was rendered isotonic with glucose before injection. Sufficient deuterium oxide was injected from a calibrated syringe to provide an equilibrium concentration of approximately $0.25 \mathrm{ml}$. per $100 \mathrm{ml}$. of body water. The deuterium oxide content of serum water was determined by the falling drop method (13, 14). In all cases serial determinations of the serum $\mathrm{D}_{2} \mathrm{O}$ concentration indicated that equilibrium had been attained within two hours.

The volume of distribution of inulin was measured by the constant infusion technique as described by Schwartz and his co-workers $(15,16)$. A priming injection of inulin was followed by a constant sustaining infusion for 14 to 20 hours. Assuming a volume of distribution of 17 per cent of body weight, the prime was calculated to yield a plasma concentration of 20 to $40 \mathrm{mg}$. per cent. The concentration of sustaining infusion was calculated on an assumed filtration rate. All inulin solutions were made up in sterile pyrogen-free 5 per cent dextrose in distilled water. Constancy of the infusion rate was maintained with a Bowman constant infusion pump, calibration of which in successive 15,30 , and 60 -minute periods revealed variation of less than 1 per cent in the volume flow per minute. Shortly before stopping the infusion a final blood sample was drawn. The bladder was washed well with distilled water and air through the multi-eyed catheter. At completion of the "wash-out" the infusion was discontinued and the urine was collected until all the inulin had been excreted. By 24 hours urinary recovery of inulin was at least 98 per cent in every case.

- Sterile, pyrogen-free deuterium oxide with a concentration of 99.8 per cent $\mathrm{D}_{2} \mathrm{O}$ was obtained from the $\mathrm{Ra}$ dioactive Pharmaceuticals Department of Abbott Laboratories. 
The volume of distribution of inulin was calculated as the quantity of inulin recovered in the urine divided by the equilibrium concentration of inulin in plasma water. Inulin analyses were performed by Harrison's modification (17) of the method of Alving, Rubin, and Miller (18). Since constancy of plasma inulin concentration was always obtained and since the rate of inulin excretion was equal to the constant rate of infusion in every case by the time the sustaining infusion was discontinued, it is probable that equilibrium distribution of inulin was achieved in each study.

The thiosulfate space was determined as follows: Ten to thirteen grams of sodium thiosulfate 7 (as a 10 to 13 per cent solution) were given intravenously during a 10 to 12-minute period from a syringe which had been calibrated at $20^{\circ} \mathrm{C}$, with mercury or water at arbitrary marks. A minimum of four blood samples, evenly spaced over 20 to 70 minutes after the start of the infusion,

7 The sodium thiosulfate (Sulfactol 8 ) used in these studies was generously supplied by Vincent P. Carr of Winthrop-Stearns, Inc. were drawn. Serum thiosulfate concentrations were plotted semilogarithmically against the mid-time of sample collection, and the equilibrium concentration was obtained by extrapolation to the time of commencement of infusion. The extrapolated concentration was divided into the dose injected to obtain the volume of distribution (19). Thiosulfate analyses were performed by the indirect iodometric macro-method of Newman, Gilman, and Philips in which $1 \mathrm{ml}$. of $0.01 \mathrm{~N}$ thiosulfate equals 8 $m l$. of $0.01 \mathrm{~N}$ iodate $(20)$.

In the patients maintained on the "normal" diet the extracellular fluid space was determined simultaneously with inulin and thiosulfate in every instance. In the patients on the "restricted" diet the extracellular fluid space was determined by the inulin technique alone, except in the very last study (i.e., after having been replaced on the "normal" diet) when thiosulfate was used. In every instance where the volumes of distribution of inulin and of thiosulfate were simultaneously determined there was satisfactory experimental agreement (less than 2 per cent variation), indicating that inulin and thiosulfate ap-

\section{EFFECTS OF IONIZING RADIATION Normal Diet}

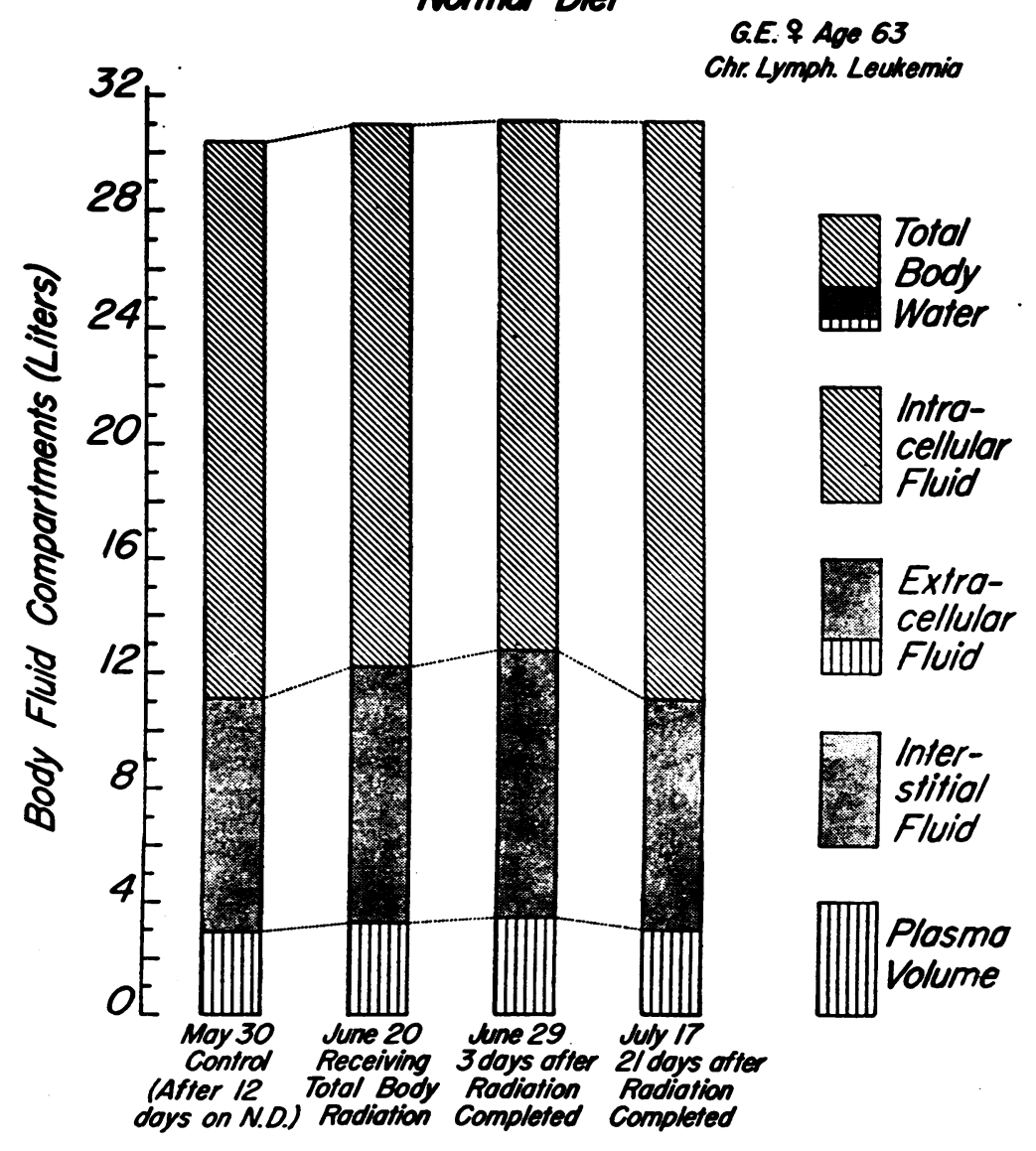

FIGURE 1. 


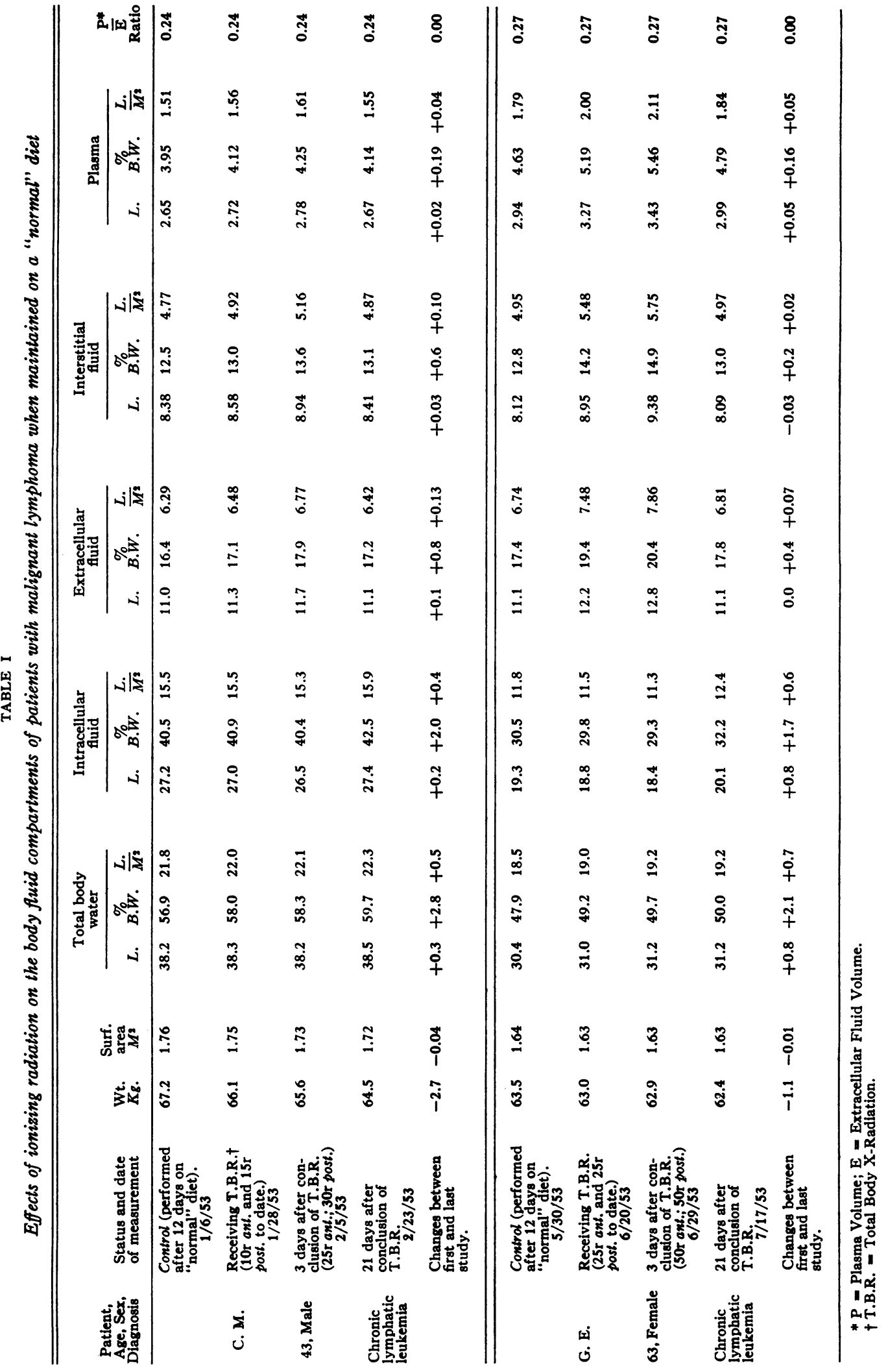


pear to have the same volume of distribution in these patients.

The $I^{1 \mathrm{x}}$-tagged human serum albumin space was determined by injecting intravenously a tracer dose (approximately $50 \mu \mathrm{c}$ ) of I.H.S.A. ${ }^{8}$ from a calibrated syringe and measuring the dilution of activity which resulted in the specimen of plasma drawn 10 minutes after the time of injection. The I.H.S.A. content of plasma was determined by diluting $5 \mathrm{ml}$. of plasma to $100 \mathrm{ml}$. with isotonic saline in a Marinelli beaker which was then placed around a gamma-sensitive bismuth cathode tube. The activity of the sample was compared with that of a standard suitably prepared in duplicate at the time of administration of the I.H.S.A. to the patient. Uranium standards were used to verify the stability of the counting equipment throughout the investigation. In all cases serial determinations of the plasma $I^{m-a c t i v i t y ~}$ indicated that equilibrium had been attained by 10 minutes.

The intracellular fluid volume was calculated as the difference between the simultaneous volumes of distribution of heavy water and inulin or thiosulfate. The interstitial fluid volume was calculated as the difference between the simultaneous volumes of distribution of inulin and/or thiosulfate and I.H.S.A.

These methods of determining the body fluid compartments gave values which were reproducible within 3 per cent in the same individual under constant conditions.

The order of administration of the various materials was as follows: The constant infusion of inulin was begun at 6 p.m. of the night preceding the study. On the morning of the study the plasma volume was determined, then the thiosulfate and deuterium oxide were injected and at the appropriate times blood samples removed for the determination of their volumes of distribution. After this the inulin constant infusion was terminated and the urine collected for inulin.

\section{RESULTS}

\section{"Normal" diet}

The pertinent experimental data are presented in Table $I$ and Figure 1.

Control phase. During this phase the volumes of distribution of deuterium oxide and inulin and/ or thiosulfate were within the limits accepted as normal in both patients. The I.H.S.A. space was within the normal range in patient G. E. (2.94 L. or $1.79 \mathrm{~L}$. per $\mathrm{M}^{2}$ ), but in C. M. it was somewhat contracted (2.65 L. or $1.51 \mathrm{~L}$. per $\mathrm{M}^{2}$ ).

8 The $\mathrm{I}^{12 \mathrm{x}}$-tagged human serum albumin was obtained from the Radioactive Pharmaceuticals Department of Abbott Laboratories. All lots were dialyzed in the cold against frequently changed normal saline solutions for 48 to 72 hours, so that all solutions of I.H.S.A. injected into the patients contained less than 1 per cent free $I^{12}$.
Radiation phase. The heavy water space did not show any striking changes under the influence of radiation, the maximum change being an increase of $0.8 \mathrm{~L}$. in G. E. The extracellular fluid volume, however, was significantly expanded in both patients $(0.7$ L. in C. M.; 1.7 L. in G. E.). This expansion was at the expense of the intracellular compartment which was concomitantly reduced by 0.7 L. in C. M. and by $0.9 \mathrm{~L}$. in G. E. The interstitial fluid and plasma volumes increased during this phase in both patients, the expansion being proportional to the increase in the extracellular fluid volume. Thus, the ratio of the plasma volume to the extracellular fluid volume remained constant in both patients ( 0.24 in C. M. ; 0.27 in G. E.).

Post-radiation phase. Re-study of the fluid compartments 21 days after the last dose of total body $\mathrm{x}$-radiation had been given showed that by that time there was essentially complete restoration of the various spaces to control levels in both patients.

\section{"Deficient" diet}

The pertinent experimental data are presented in Table II and Figure 2.

Control phase. Here, as in the patients receiving a "normal" diet the total body water and extracellular fluid volumes were within normal limits. The plasma volume was moderately contracted (I.H.S.A. space of 2.23 L. or 1.36 L. per $\mathrm{M}^{2}$ in I. T. and $2.49 \mathrm{~L}$. or $1.60 \mathrm{~L}$. per $\mathrm{M}^{2}$ in S. C.).

Radiation phase. In sharp contrast to the patients receiving a "normal" diet, both patients on the "restricted" diet showed a significant decrease in their total body water $(2.4 \mathrm{~L}$. in I. T. and $4.0 \mathrm{~L}$. in S. C.). At the same time there was an even larger expansion of the extracellular fluid than in the patients who were maintained on the "normal" diet (2.0 L. in I. T. and 2.3 L. in S. C.). The resulting reduction in the intracellular fluid volume was therefore considerable $(4.4 \mathrm{~L}$. in $\mathrm{I}$. $\mathrm{T}$. and 6.3 L. in S. C.). The interstitial fluid and plasma volumes increased as in the patients receiving the "normal" diet. This expansion was likewise directly proportional to the increase in the extracellular fluid volume.

Post-radiation phase. The body fluid compartments were re-measured 13 days (I. T.) and 


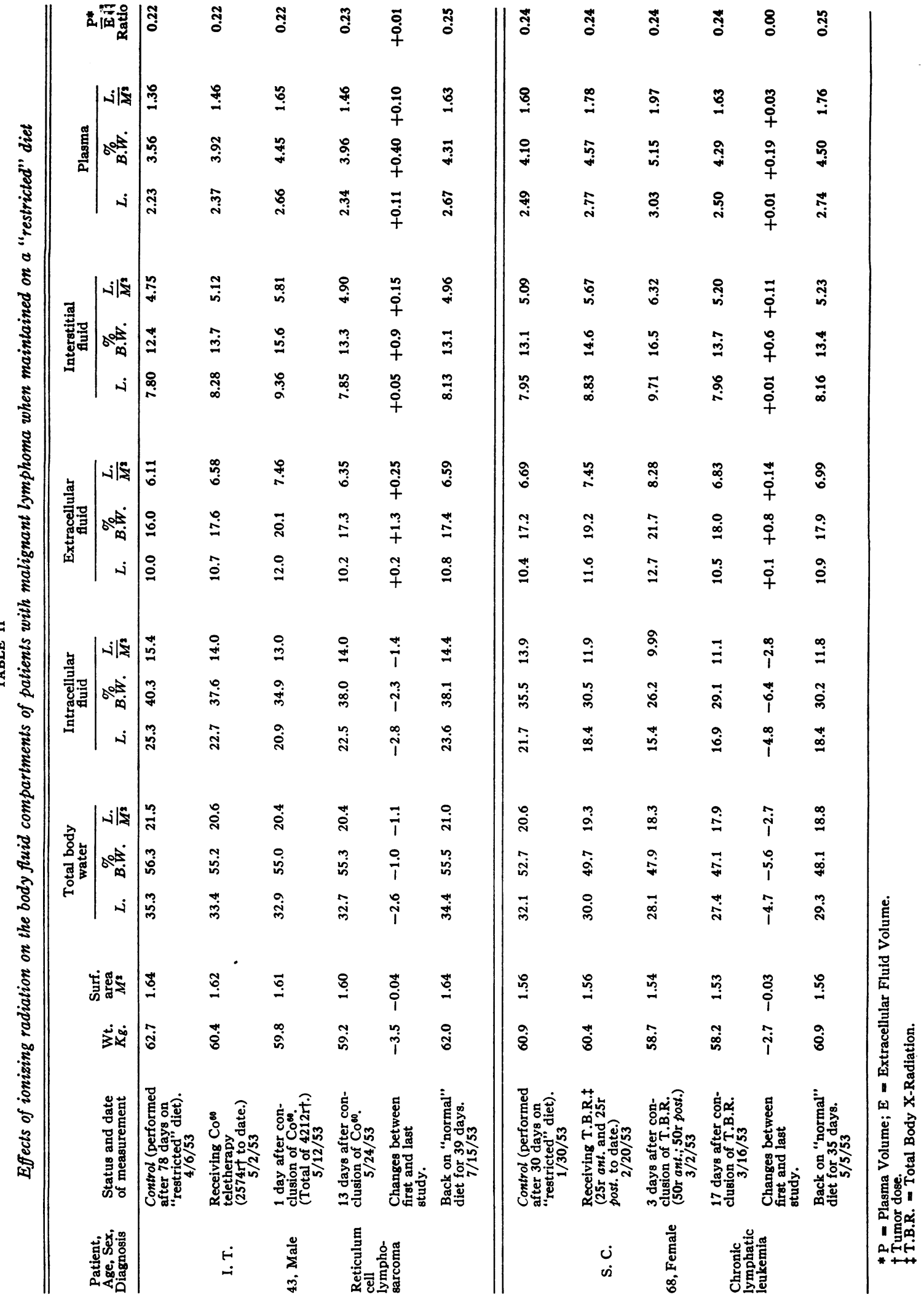


EFFECTS OF NONIING RADIATION Restricted Diet

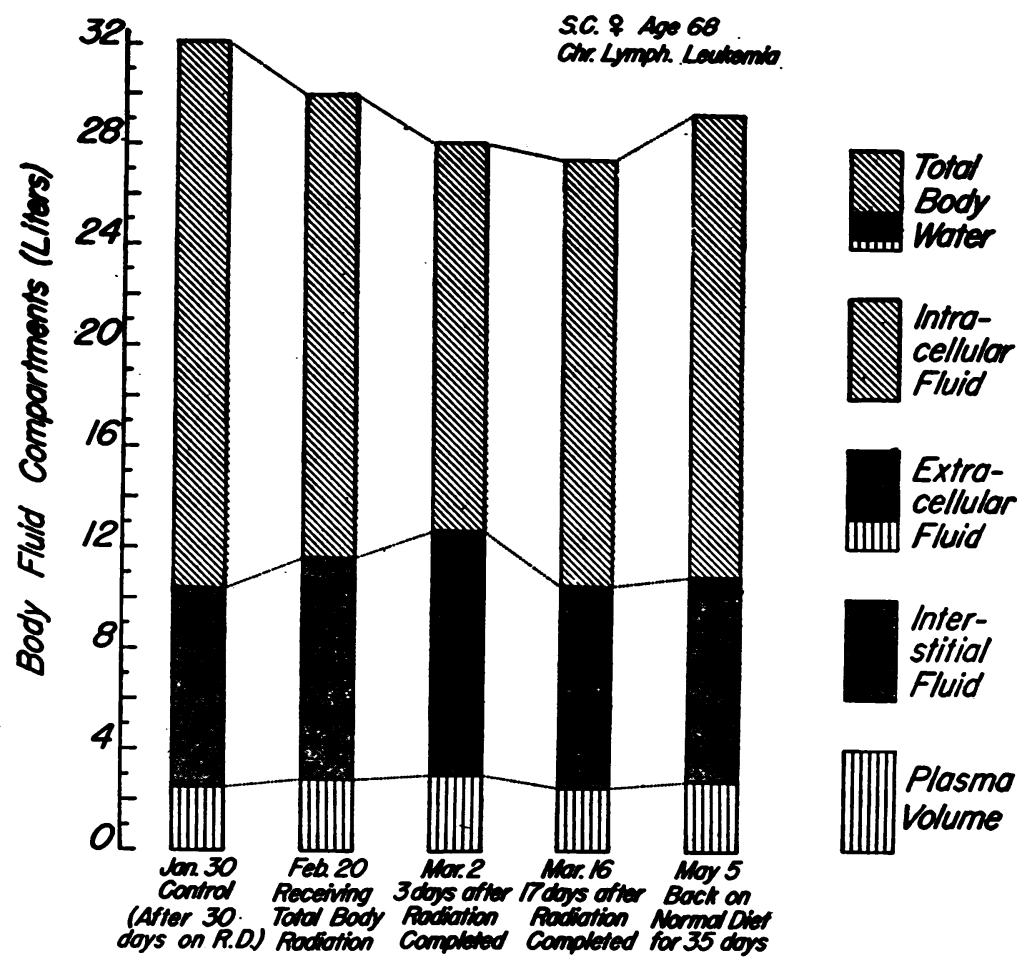

FIGURe 2.

17 days (S. C.) after the conclusion of radiation. As in the patients on "normal" diet here too there was a return of the plasma, interstitial, and extracellular fluid volumes to control levels. Most of the water leaving the extracellular fluid returned to the cells (1.6 L. out of a possible $1.8 \mathrm{~L}$. in I. T., and $1.5 \mathrm{~L}$. out of a possible $2.2 \mathrm{~L}$. in S. C.). Despite this, and in sharp contrast to the patients on the "normal" diet, the total body water, and hence the intracellular fluid volume of the patients on the "restricted" diet remained markedly reduced as compared to the control values.

Re-study of patients S. C. and I. T. 35 and 39 days, respectively, after being replaced on a "normal" diet

Both patients showed an expansion of all the body fluid spaces as compared to the last postradiation study (cf. Table II and Figure 2). These changes are similar to those obtained by other workers in patients returning from a Kempner regimen to a "normal" $\operatorname{diet}(21,22)$. The plasma volume, interstitial fluid volume, and hence the extracellular fluid volume increased above the levels found in the initial (control) study. In both patients the plasma volume expanded somewhat more than did the interstitial fluid volume so that the ratio of plasma volume to extracellular fluid volume increased slightly. There was also expansion of the intracellular fluid volume and total body water which, while significant, did not raise these spaces to the levels found in the control study.

\section{DISCUSSION}

Changes in the extracellular fluid and plasma volumes, similar to those reported here for man have been previously described in animals exposed to ionizing radiation. Thus, Prosser, Painter, and Swift found an increase in extracellular fluid as measured by the thiocyanate space and an expanded plasma volume ( $\mathrm{T}-1824$ space) in dogs given lethal and near-lethal doses of total body x-radiation (5). Soberman, Keating, and Maxwell, using the $\mathrm{P}^{\text {s2 }}$-tagged red cell 
technique, observed an increase in the plasma volumes of all their dogs given 450 to $500 \mathrm{r}$ total body x-radiation (10). Ferrell, Turner, and Overman reported an expansion of the plasma volumes ( $\mathrm{T}-1824$ space) of monkeys given total body $\mathrm{x}$-radiation both in their 24 and 48-hour studies and at both the 400 and 500r dose levels (11). France found increases in plasma volume ( $\mathrm{T}-1824$ space) and extracellular fluid volume (thiocyanate space) and a decrease in intracellular fluid volume following the administration of near lethal doses of total body $\mathrm{x}$-radiation to rats and mice (3). As previously pointed out, the lack of simultaneous or serial determinations and the use of techniques such as the thiocyanate method to measure the extracellular fluid volume present considerable difficulty in the interpretation of many of these animal experiments. Therefore, in the studies here described all determinations were carried out simultaneously, and were repeated serially at given intervals. Furthermore, the reliability of the substances used in this study to measure the various fluid compartments, viz., deuterium oxide, inulin and $\mathrm{I}^{131}$-tagged human serum albumin has been confirmed by many workers $(13,15,16,23-29)$. The use of the volume of distribution of the thiosulfate ion as a measure of extracellular fluid volume has been suggested by Cardoza and Edelman (19) and in the present study there was excellent experimental agreement between the thiosulfate and inulin spaces whenever these two measurements were carried out simultaneously.

The radiation-induced expansion of the volumes of distribution of inulin and thiosulfate observed in these patients was probably due to a true increase in the extracellular fluid volume rather than to an increase in permeability of the cell membrane to, or changes in the metabolism of, these substances. Thus, inulin and thiosulfate, despite very significant differences in molecular size, configuration, charge and metabolic fate, exhibited the same volume of distribution whenever their spaces were simultaneously determined. Likewise, the expansion in the albumin space observed following radiation was also probably a true increase in the plasma volume and not the result of increased permeability of the capillaries to albumin. Thus, multiple serial samples of plasma obtained between 10 and 15 minutes revealed no significant differ- ence in activity during the radiation phase as well as in the control and post-radiation phases. Furthermore, the ratio of the plasma volume to the extracellular fluid volume remained constant throughout. This constancy of the ratio could be achieved if there occurred a proportionate increase in capillary permeability for albumin and cell membrane permeability for both inulin and thiosulfate. This, however, is quite unlikely if due only to the large differences in the sizes of these molecules. A much more tenable hypothesis to explain the constancy of the ratio of the plasma volume to the extracellular fluid volume is that the water which leaves the cells as the result of the radiation injury then distributes itself equally throughout all parts of the extracellular fluid. Since the capillary membrane is not a barrier for water one could readily accept this thesis which then assumes that the extracellular fluid acts as a one compartment system with regard to a substance like water.

The changes which were observed in the fluid compartments of the patient who received local radiotherapy were similar to those seen in the patients who were given total body radiation. This suggests that ionizing radiation to any tissue area may result in the release into the circulation of substances like histamine which may then $d i$ rectly cause generalized cellular injury. Alternately, there are many investigators who believe that various forms of stress, such as radiation, cause the elaboration of substances like histamine in the organism and that these in turn initiate a secondary response of the pituitary-adrenal axis. Indeed, France has pointed out that "many of the changes in water metabolism and in other body functions that follow irradiation, especially in large doses, appear to parallel those that occur after administration of large amounts of desoxycorticosterone acetate or other adrenal hormones to normal animals" (3). Patt, Swift, Tyree, and John have noted that radiated animals show definite adrenal cortical hypertrophy (30). In 1942, Leblond and Segal radiated distal portions of animals, carefully shielding the rest of the body and found thymus atrophy, lymphopenia, and fatty livers. If the pituitary or adrenals were removed, no such changes were observed (31). Similar results were obtained by Dougherty and White in 1946 (32). These data strongly sup- 
port the thesis that radiation imposes a stress upon the organism which initiates the "adaptation syndrome" with consequent increased activity of the pituitary-adrenal axis.

All the patients in this study manifested an expansion of the extracellular fluid volume at the expense of the intracellular compartment following exposure to ionizing radiation. It seems likely, therefore, that following exposure to ionizing radiation there occurred a cellular injury leading to a loss of intracellular constituents including water. This resulted in an expansion of the extracellular fluid volume including the plasma. This shift may be reversible following the cessation of the radiation. Thus, in the post-radiation phase the patients maintained on "normal" diet had a return of their various fluid compartments to preradiation levels.

However, if the radiation dose is too large or the cell very radio-sensitive, irreversible cell destruction may occur resulting in the permanent escape of the intracellular constituents (water, nitrogen, phosphorus, potassium, etc.) to the extracellular environment and/or to the external world, with the appearance of the end products of tissue catabolism in the excreta. Thus, in this study, patient $C$. $M$. who received the least radiation also showed the smallest changes in his body fluid compartments as well as the smallest clinical and metabolic response. Furthermore, both patients maintained on the "restricted" diet showed a very marked clinical and catabolic response to the ionizing radiation. They showed striking regression of their lesions and marked negativity in their nitrogen, phosphorus, and potassium balances as well as marked increases in uric acid excretion (33). They also showed a very significant teduction in lean body mass (34), and heavy water space, with marked contraction of the intracellular fluid volume. Following cessation of the radiation most of the water which left the extracellular fluid returned to the cells. Despite this, however, and in contrast to the patients on the "normal" diet, the total body water and hence the intracellular fluid volume remained markedly reduced as compared to the control levels. These differences in the response to radiation could mean that the "restricted" diet may have in some way made the tissues more radiosensitive, resulting in an enhancement of the radiation effects.

\section{SUMMARY}

The effects of ionizing radiation were studied in four patients with maligant lymphomas under controlled metabolic conditions. Throughout the entire study two of the patients were maintained on a "normal" diet; two received a diet adequate in calories, low in protein and deficient in B-vitamins and certain minerals (modified Kempner rice diet). Serial simultaneous determinations of the body fluid compartments were performed in conjunction with other studies such as measurements of the metabolic balances.

During the control phase, except for a moderate plasma volume contraction observed in some of the patients, the fluid compartments were within normal limits. Ionizing radiation caused expansion of the extracellular fluid and plasma volumes at the expense of the intracellular compartment in all cases. The reduction in intracellular volume was much more marked in the patients on the "restricted" diet. Furthermore, the total body water decreased significantly and remained reduced during the entire period of post-radiation observation (two to three weeks) in the patients on the "restricted" diet. The extracellular fluid and plasma volumes, however, returned to preradiation levels within this period in all cases. The implications of these findings and their correlation with possible mechanisms of radiation injury are discussed.

\section{APPENDIX}

\section{Clinical Data}

1. C. M. (M. H. No. 60274), a 43-year-old male who complained of excessive fatigue and pallor for one month prior to admission. White blood count (W. B. C.) revealed 90,000 cells per $\mathrm{mm}^{2}$. with more than 75 per cent mature lymphocytes. Hemoglobin ( $\mathrm{Hgb}$.) was 10.5 grams per $100 \mathrm{ml}$. Past history revealed nervousness, perspiration, and palpitation on exertion of 15 years' duration. The patient was referred to this hospital for further evaluation.

Physical examination. Temperature, $100^{\circ} \mathrm{F}$, blood pressure, $158 / 88 \mathrm{~mm}$. $\mathrm{Hg}$, pulse rate, 100 per min., regular. There was moderate pallor. The liver extended down to 3 finger breadths below the right costal margin and the spleen down to 2 finger breadths below the left costal margin. There was no significant adenopathy.

Laboratory findings. Hgb. 10.5 grams; red blood count (R. B. C.) 3.51 million per $\mathrm{mm}^{2}$., W. B. C. 56,000 with 80 per cent mature lymphocytes; platelet count (direct method) 186,000 per $\mathrm{mm}^{2}$. Sternal marrow as- 
piration showed 92 per cent lymphocytes in different stages of maturation. Im $I^{13}$ uptake studies showed a borderline pattern between euthyroid and hyperthyroid levels. Blood chemistries, EKG, roentgenograms and other laboratory data were essentially normal.

Course. The patients was given total body $\mathrm{x}$-radiation as outlined in the section on procedure. There was no essential change in the hepatosplenomegaly. The temperature, however, became normal. The W. B. C. fell to 27,000 with 72 per cent mature lymphocytes. R. B. C. was 3.72 million; Hgb. 11.0 grams; platelet count 262,000. Sternal bone marrow revealed 75 per cent lymphocytes in different stages of maturation, but with more mature forms than originally. The erythroid and megakaryocytic elements were somewhat more numerous than prior to radiotherapy. The patient was asymptomatic at this time.

2. G. E. (M. H. No. 57022), a 63-year-old housewife with proven chronic lymphatic leukemia of at least 12 years' duration. Treatment during this period with blood transfusions, urethane, triethylene melamine, and radiotherapy (both local and total body $x$-radiation), gave varying degrees of response. The remainder of the history was essentially unremarkable, and on the present admission her only complaint was "weakness."

Physical examination. Temperature, $100^{\circ} \mathrm{F}$., Blood pressure, $112 / 74 \mathrm{~mm}$. $\mathrm{Hg}$, pulse rate, 90 per min., regular. There was moderate pallor. The liver extended down to 2 finger breadths below the right costal margin, and the spleen down to 2 finger breadths below the left costal margin. There was generalized adenopathy (up to $2.0 \mathrm{~cm} . \times 1.5 \mathrm{~cm}$.).

Laboratory findings. Hgb. 8.5 grams; R. B. C. 3.28 million per $\mathrm{mm}^{3}$., W. B. C. 211,000 with 91 per cent lymphocytes and 4 per cent lymphoblasts; platelet count $122,000 \mathrm{~mm}^{2}$. Sternal marrow aspiration revealed almost complete replacement by lymphocytes, some of which were early forms. E. K. G. showed left axis deviation. Blood chemistries, roentgenograms and other laboratory data were essentially normal.

Course. The patient was given total body $\mathrm{x}$-radiation as outlined in the section on procedure. There was only minimal decrease in the size of the nodes, liver, and spleen, and the patient continued to have daily temperature elevations to $100^{\circ}$ F. The W. B. C., however, was reduced to 31,000 of which 90 per cent were mature lymphocytes and the remainder normal cells of the granulocytic series. R. B. C. fell to 1.87 million and Hgb. to 4.5 grams. Platelet count 84,900 . Sternal marrow revealed 85 per cent mature lymphocytes; there was some increase in the number of myeloid, megakaryocytic, and erythroid elements as compared to the preradiation specimen, although all these elements were still markedly reduced in number. The patient continued to complain of "weakness," which was greatly improved following blood transfusion.

3. S. C. (M. H. No. 57153), a 68-year-old housewife who developed generalized malaise 10 months prior to admission. Examination revealed hepatosplenomegaly, generalized adenopathy and a W. B. C. of 317,000 with
99 per cent mature lymphocytes. The remainder of the history was essentially negative except for moderate exertional dyspnea for the past two years. The patient received blood transfusions and three courses of total body $x$-radiation. The hepatosplenomegaly and adenopathy were essentially unaffected but the white count was temporarily reduced after each course of radiation. Just prior to admission the patient developed a bronchopneumonia which responded to antibiotics, but she complained of "feeling weak," and was referred to the metabolic service.

Physical examination. Temperature, $100^{\circ}$ F., blood pressure, $172 / 88 \mathrm{~mm}$. $\mathrm{Hg}$, pulse rate, 90 per min., regular. There was moderate pallor. The liver and spleen extended down to the right and left iliac crest, respectively. There was marked generalized adenopathy (up to $6.0 \mathrm{~cm}$. by $6.0 \mathrm{~cm}$.).

Laboratory findings. Hgb. 8.5 grams; R. B. C. 3.10 millions per $\mathrm{mm}^{3}$., W. B. C. 350,000 with 98 per cent mature lymphocytes; platelet count 143,000 per $\mathrm{mm}^{2}$. Sternal marrow aspiration revealed 95 per cent mature lymphocytes. E. K. G. showed left axis deviation. Chest plate revealed enlargement of the left ventricle and thickened pleura in the right mid-lung field. Blood chemistries and other laboratory data were essentially normal.

Course. The patient was placed on the "restricted" diet and given total body $\mathbf{x}$-radiation as outlined in the section on procedure. There was no essential change in the size of the liver or spleen. The adenopathy, however, was very strikingly reduced and the temperature became normal. The W. B. C. fell to 12,000 of which 95 per cent were mature lymphocytes. The R. B. C. dropped to 2.68 million and the $\mathrm{Hgb}$. to 6.8 grams. Platelet count 128,000 . The sternal marrow was similar to the pre-radiation specimen. The patient was asymptomatic at this time.

4. I. T. (M. H. No. 60032), a 43-year-old male with a previously negative history who had a suspicious shadow in the left superior mediastinum on chest x-ray. Exploratory thoracotomy revealed an inoperable reticulum cell sarcoma. During the next four months the patient received local $x$-ray therapy to the site of the lesion with considerable regression of the mass. However, there was massive recurrence two months thereafter.

Physical examination. Temperature, $99^{\circ}$ F., blood pressure, $120 / 70 \mathrm{~mm}$. $\mathrm{Hg}$, pulse rate, 90 per min., regular. The trachea was shifted somewhat to the right, and there was left cervical and supraclavicular adenopathy, but the lungs appeared clear to percussion and auscultation. There were no other abnormal masses.

Laboratory findings. Essentially normal blood count, platelet count, bone marrow, blood chemistries, and E. K. G. Chest x-ray revealed a large left superior mediastinal density.

Course. The patient was placed on the "restricted" diet and given Cobalt ${ }^{\infty}$ teletherapy as outlined in the section on procedure. The masses in the left cervical and supraclavicular area diminished very markedly in size, and there was considerable reduction in the size 
of the left upper chest shadow. The patient was entirely asymptomatic at this time.

\section{ACKNOWLEDGMENT}

The authors gratefully acknowledge the cooperation and advice of Dr. J. R. Freid and his staff of the Radiotherapy Department. They also express their appreciation for the technical aid of Mr. Frank Sciancalepore, and for the assistance given by Mrs. Vernice Vankinscott, R.N., and Miss Estelle D. Gottesman, research dietitian.

\section{REFERENCES}

1. Liebow, A. A., Warren, S., and DeCoursey, E., Pathology of atomic bomb casualties. Am. J. Path., 1949, 25, 853.

2. Rugh, R., Effect of $x$-irradiation on tissue hydration in the mouse. Nucleonics, 1954, 12, 28.

3. France, O., Changes in the water content and distribution in rats and mice after chronic and acute total-body x-irradiation. AEC Report CH-3889, 1946.

4. Prosser, C. L., Painter, E. E., Lisco, H., Brues, A. M., Jacobson, L. O., and Swift, M. N., The clinical sequence of physiological effects of ionizing radiation in animals. Radiology, 1947, 49, 299.

5. Prosser, C. L., Painter, E. E., and Swift, M. N., The clinical physiology of dogs exposed to single total-body doses of x-rays. AEC Report MDDC1272, 1947.

6. Painter, E. E., Prosser, C. L., and Moore, M. C., Physiological observations on rabbits exposed to single doses of x-rays. AEC Report MDDC-761, 1947.

7. Nims, L. F., and Sutton, E., Weight changes and water consumption of rats exposed to whole body x-irradiation. Am. J. Physiol., 1952, 171, 17.

8. Gustafson, G. E., and Koletsky, S., Nitrogen metabolism following whole body $\mathbf{x}$-radiation. Am. J. Physiol., 1952, 171, 319.

9. Brues, A. M., Sacher, G., and France, H. O., Effect of total body $x$ ray on weights of organs in the rat. AEC Report MDDC-1197, 1946.

10. Soberman, R. J., Keating, R. P., and Maxwell, R. D., Effect of acute whole-body $\dot{x}$-irradiation upon water and electrolyte balance. Am. J. Physiol., 1947, 164, 450.

11. Ferrell, C. B., Turner, M. D., and Overman, R. R., Alterations in transcapillary exchange and hemodynamics in monkeys subjected to whole body $x$-radiation. Federation Proc., 1954, 13, 43.

12. Kempner, W., Compensation of renal metabolic dysfunction. Treatment of kidney disease and hypertensive vascular disease with rice diet. North Carolina M. J., 1945, 6, 61, 117.

13. Schloerb, P. R., Friis-Hansen, B. J., Edelman, I. S., Solomon, A. K., and Moore, F. D., The measurement of total body water in the human subject by deuterium oxide dilution. With a consideration of the dynamics of deuterium distribution. J. Clin. Invest., 1950, 29, 1296.

14. Schloerb, P. R., Friis-Hansen, B. J., Edelman, I. S., Sheldon, D. B., and Moore, F. D., The measurement of deuterium oxide in body fluids by the falling drop method. J. Lab. \& Clin. Med., 1951, 37, 653.

15. Schwartz, I. L., Schachter, D., and Freinkel, N., The measurement of extracellular fluid in man by means of a constant infusion technique. J. Clin. Invest., 1949, 28, 1117.

16. Schwartz, I. L., Breed, E. S., and Maxwell, M. H., Comparison of the volume of distribution, renal and extrarenal clearances of inulin and mannitol in man. J. Clin. Invest., 1950, 29, 517.

17. Harrison, H. E., A modification of the diphenylamine method for determination of inulin. Proc. Soc. Exper. Biol. \& Med., 1942, 49, 111.

18. Alving, A. S., Rubin, J., and Miller, B. F., A direct colorimetric method for the determination of inulin in blood and urine. J. Biol. Chem., 1939, 127, 609.

19. Cardoza, R. H., and Edelman, I. S., The volume of distribution of sodium thiosulfate as a measure of the extracellular fluid space. J. Clin. Invest., 1952, 31, 280.

20. Newman, E. V., Gilman, A., and Philips, F. S., The renal clearance of thiosulfate in man. Bull. Johns Hopkins Hosp., 1946, 79, 229.

21. Murphy, R. J. F., The effect of "rice diet" on plasma volume and extracellular fluid space in hypertensive subjects. J. Clin. Invest., 1950, 29, 912.

22. Watkin, D. M., Froeb, H. F., Hatch, F. T., and Gutman, A. B., Effects of diet in essential hypertension. II. Results with unmodified Kempner rice diet in fifty hospitalized patients. Am. J. Med., 1950, 9, 441.

23. Levitt, F. F., and Gaudino, M., Measurement of body water compartments. Am. J. Med., 1950, 9, 208.

24. Krieger, H., Storaasli, J. P., Friedell, H. L., and Holden, W. D., A comparative study of blood volume in dogs. Proc. Soc. Exper. Biol. \& Med. 1948, 68, 511.

25. Storaasli, J. P., Krieger, H., Friedell, H. L., and Holden, W. D., The use of radioactive iodinated plasma protein in the study of blood volume. Surg., Gynec. \& Obst., 1950, 91, 458.

26. Aust, J. B., Chou, S. N., Marvin, J. F., Brackney, E. L., and Moore, G. E., A rapid method for clinical total blood volume determination using radioactive iodinated human serum albumin ( $R$ I H S A). Proc. Soc. Exper. Biol. \& Med., 1951, 77, 514.

27. Crispell, K. R., Porter, B., and Nieset, R. T., Studies of plasma volume using human serum albumin tagged with radioactive iodine $\mathrm{e}^{\mathrm{m}}$. J. Clin. Invest., 1950, 29, 513.

28. Schultz, A. L., Hammarsten, J. F., Heller, B. I., and Ebert, R. V., A critical comparison of the T-1824 
dye and iodinated albumin methods for plasma volume measurement. J. Clin. Invest., 1953, 32, 107.

29. Freinkel, N., Schreiner, G. E., and Athens, J. W., Simultaneous distribution of $T-1824$ and $I^{1 m}$-labelled human serum albumin in man. J. Clin. Invest., 1953, 32, 138.

30. Patt, H. M., Swift, M. N., Tyree, E. B., and John, E. S., Adrenal response to total body $x$-radiation. Am. J. Physiol., 1947, 150, 480.

31. Leblond, C. P., and Segal, G., Differentiation between the direct and indirect effects of roentgen rays upon the organs of normal and adrenalectomized rats. Am. J. Roentgenol., 1942, 47, 302.
32. Dougherty, T. F., and White, A., Pituitary-adrenal cortical control of lymphocyte structure and function as revealed by experimental $x$-radiation. Endocrinology, 1946, 39, 370.

33. Spencer, H., Greenberg, J., and Laszlo, D., Effects of ionizing radiation and of dietary restriction on patients with malignant lymphoma. A metabolic study. Proc. Am. Assoc. for Cancer Research, 1954, $1,46$.

34. Greenberg, J., Weisz, P., and Laszlo, D., Effects of ionizing radiation and of dietary restriction on body composition of patients with malignant lymphoma. Proc. Am. Assoc. for Cancer Research, 1954, 1, 16.

\section{ANNOUNCEMENTS OF MEETINGS}

The 47th Annual Meeting of the American Society for Clinical Investigation will be held in Atlantic City, N. J., on Monday, May 2, 1955, with headquarters at the Chalfonte-Haddon Hall. The scientific session will begin at 9 a.m. at the Steel Pier Theater.

The annual meeting of the Association of American Physicians will be held at the Steel Pier Theater on Tuesday, May 3, and at the Chalfonte-Haddon Hall on Wednesday morning, May 4, 1955. 